\title{
Telenovela e memória: "Vale a pena ver de novo?", reprises em tempo de pandemia
}

\section{Television and memory: "Vale a pena ver de novo?", replays in pandemic times}

Nilda Jacks ${ }^{1}$, Guilherme Libardi ${ }^{2}$, Joselaine Caroline ${ }^{3}$ e Vanessa Scalei ${ }^{4}$

1 Nilda Jacks é professora titular no PPGCOM/UFRGS. Bolsista Produtividade em Pesquisa do CNPq. E-mail: njacks@terra.com.br

3 Joselaine Caroline é doutoranda pelo Programa de Pós-Graduação em Comunicação da UFRGS. E-mail: joselaine.caroline@ufrgs.br.

4 Vanessa Scalei é jornalista e doutoranda pelo Programa de Pós-Graduação em Comunicação da PUCRS. E-mail: vanessa.scalei@edu.pucrs.br. 


\section{Resumo}

Este artigo tem como objetivo observar as práticas de consumo de telenovela pela audiência em contexto de isolamento social provocado pela pandemia do novo coronavírus. Partimos das discussões inerentes ao papel da narrativa ficcional para a memória, buscando evidenciar como ela é atualizada na assistência de reprises. Identificamos as estratégias adotadas pelas principais emissoras brasileiras para se adaptar ao momento em questão. Após, divulgamos um questionário online com perguntas relacionadas à assistência de reprises, reunindo 265 respostas. Identificamos que no contexto de isolamento o consumo de telenovelas aumentou, sendo que a nostalgia foi o principal motivador desse retorno. Nesse movimento, novos sentidos foram inaugurados pela audiência, tecidos por mudanças de postura em relação a temas específicos abordados nas narrativas revisitadas.

\section{Palavras-chave}

Telenovela, reprise, pandemia, audiências, memória.

\section{Abstract:}

This paper aims at observing the soap-opera's consumption practices by the audience in the social isolation context caused by the coronavirus pandemic. Starting from discussions inherent to the role of the fictional narratives for the memory, seeking to provide evidence on how it is updated upon replay session exhibits. The strategies adopted by the main Brazilian TV stations in order to adapt to the current situation were identified. Then, an online survey was deployed concerning questions on replay session exhibits, gathering 265 responses. The isolation context made it possible to realize that the soap-opera's consumption has increased, and nostalgia was the main motivation for such level of response. Due to that input, new meanings were inaugurated by the audience, being structured by changes in attitude regarding specific themes that are approached in the narratives that were being revisited.

\section{Keywords}

Soap-opera, replay, pandemic, audience, memory. 
Narrativas alimentaram por séculos a cultura oral, por outros mais a cultura logocêntrica e continuam alimentando, há pouco mais de um século, a cultura audiovisual. O cinema e, depois, a televisão recodificaram seus formatos e suas linguagens, sendo a telenovela o principal gênero narrativo televisivo, em se tratando da televisão brasileira. Parte da memória social e cultural pertence ao âmbito dessa produção midiática já com longa história no cenário nacional. A primeira telenovela diária, 2-5499 Ocupado, foi ao ar em 1963 pela extinta TV Excelsior, e a Globo, que se tornou hegemônica nessa seara a partir da década de 1970 (FERNANDES, 1987), inaugurou sua produção com Ilusões Perdidas, em 1965.

Na Globo, muitas delas foram regravadas ${ }^{5}$ ou reprisadas, estratégia essa que vem ocorrendo desde 1969, quando a emissora começou a exibir telenovelas antigas na parte da tarde. Em 1976, a faixa passou a ser transmitida no horário fixo das 13h30, depois do Jornal Hoje, com a volta de Helena, originalmente exibida no ano anterior (Memória Globo). Em 1980, a sessão passou a chamar-se Vale a Pena Ver de Novo $^{6}$, com a exibição de Dona Xepa, originalmente exibida em 1977 (Teledramaturgia). Entre 1976 e 1980, foram reprisadas 11 telenovelas ${ }^{7}$. pela própria Globo, no mesmo período, para a reprise de jornalísticos. 
Na década de 1980 foram reprisadas 25 telenovelas ${ }^{8}$, na década de 1990 foram $25^{9}$, na de 2000 foram $20^{10}$ e na de 2010 foram $19^{11}$.

Quanto aos "remakes", segundo o site Memória Globo, foram 16 até o momento, começando por A Moreninha, que foi regravada na década de 1970, tendo sido exibida em 1965. As demais foram: Irmãos Coragem (1970-71/1995), Meu Pedacinho de Chão (1971-72/2015), Selva de Pedras (1972-73/1986), O Rebu (1974-75/2014), Gabriela (1975/2012), Pecado Capital (1975-76/ 1998-99), Anjo Mau (1976/1997-98), Saramandaia (1976/2013), O Astro (1977-78/ 2011), Cabocla (1979/2004), Ciranda de Pedra (1981/2008), Paraíso (1982-83/2009), Guerra dos Sexos (1983-84/ 2012-13), Ti-Ti-Ti (1985-86/2010-11) e Sinhá Moça (1986/2006). A Sucessora (1978/1980), Te Contei? (1978/1981), Cabocla - 1a versão (1979/81), Marron Glacé (1979/1982), As Três Marias (1980/1982), Moreninha - 2a versão (1975/1982), Plumas e Paetês (1980/1983), Pecado Rasgado (1978/1983), Água Viva (1980/1984), Final Feliz (1982/1984), Elas por Elas (1982/1985), Jogo da Vida (1981/1985), Feijão Maravilha (1979/1986), Paraíso - $1^{\text {a }}$ versão (1982/1986), Livre Para Voar (1984/86), Vereda Tropical (1984/1987), Amor com Amor se Paga (1984/87), Ti-ti-ti - $1^{a}$ versão (1985/1988), Gabriela - $1^{\text {a }}$ versão (1975/1988), A Gata Comeu (1985/1989), Brega \& Chique (1987/1989), Pão-Pão, Beijo-Beijo (1983/1990), Roda de Fogo (1986/1990), Sassaricando (1987/1990).

No parêntesis, o primeiro ano corresponde à veiculação original, o segundo à reprise: Top Model (1989/1991), Cambalacho (1986/1991), Fera Radical (1988/1991), Vale Tudo (1988/1992), Bebê a Bordo (1988/1992), Sinhá Moça - 1a versão (1986/1993), Barriga de Aluguel (1990/1993), Direito de Amar (1987/1993), Rainha da Sucata (1990/1994), Tieta (1989/1994), Pedra Sobre Pedra (1992/1995), Renascer (1993/1995), Despedida de Solteiro (1992/1996), Meu Bem, Meu Mal (1990/1996), Mulheres de Areia (1993/1996), A Viagem (1994/1997), Fera Ferida (1993/1997), Felicidade (1991/1998), O Salvador da Pátria (1989/1998), Quatro por Quatro (1994/1998), O Rei do Gado (1996/1999), A Indomada (1997/1999), Tropicaliente (1994/2000), A Próxima Vítima (1995/2000), Roque Santeiro (1985/2000).

No parêntesis, o primeiro ano corresponde à veiculação original, o segundo à reprise: A Gata Comeu (1985/2001, segunda reprise), História de Amor (1995/2001), Por Amor (1997/2002), O Cravo e a Rosa (2000/ 03), Anjo Mau $2^{a}$ versão (1997/2003), Corpo Dourado (1998/2004), Terra Nostra (1999/2004), Deus nos Acuda (1992/2004), Laços de Família (2000/05), Força de um Desejo (1999/2005), Chocolate com Pimenta (2003/06), Era uma Vez... (1998/2007), Da Cor do Pecado (2004/2007), Coração de Estudante (2002/2007), Cabocla - 2a versão (2004/08), Mulheres Apaixonadas (2003/2008), Senhora do Destino (2004/2009), Alma Gêmea (2005/2009), Sinhá Moça $2^{\mathrm{a}}$ versão (2006/2010), Sete Pecados (2007/2010). de Areia (1993/2011, segunda reprise), Chocolate com Pimenta (2003/2012, segunda reprise), Da Cor do Pecado (2004/2012, segunda reprise), O Profeta (2006/2013), O Cravo e a Rosa (2000/2013, segunda reprise), Caras \& Bocas (2009/2014), Cobras \& Lagartos (2006/14), O Rei do Gado (1996/2015, segunda reprise), Caminho das Índias (2009/2015), Anjo Mau - 2a versão (1997/2016, segunda reprise), Cheias de Charme (2012/2016), Senhora do Destino (2004 e 2017, segunda reprise), Celebridade (2003/2017), Belíssima (2005/2018), Cordel Encantado (2011/2019), Por Amor (1997/2019, segunda reprise), Avenida Brasil (2012/2020), Êta Mundo Bom (2016/2020), Laços de Família (2000/2020, segunda reprise). 
No contexto da pandemia da Covid-19, por sua vez, essa estratégia ganhou outra relevância e teve por motivo a garantia do isolamento social das equipes de produção. A Globo tomou a inédita decisão de tirar do ar todas as telenovelas em exibição ${ }^{12}$. Com isso, parou a gravação de Amor de Mãe no dia 16 março, colocando no lugar Fina Estampa, que havia sido veiculada entre 2011 e 2012, sendo substituída a seguir por A Força do Querer, de 2017. Simultaneamente à suspensão de Amor de Mãe, a emissora adotou ação semelhante com Salve-se Quem Puder, que ocupava a faixa das sete.

Em seu lugar, entrou a reprise de Totalmente Demais, exibida entre 2015 e 2016. Tanto Amor de Mãe quanto Salve-se Quem Puder tiveram gravações retomadas em agosto de 2020 e as exibições de capítulos inéditos estão previstas para 2021. A telenovela das seis, Éramos Seis, não foi interrompida, pois estava em suas últimas semanas no ar e as gravações encerraram em 18 de março com o roteiro sendo adaptado. Após seu término, o canal também incluiu reprises, primeiro de Novo Mundo, de 2017, e depois Flor do Caribe, de 2013. A temporada 2019-2020 de Malhação, telenovela voltada ao público jovem exibida na faixa das $17 \mathrm{~h}$, teve seu final antecipado em cerca de um mês. Uma reprise, da temporada intitulada Viva a Diferença, exibida entre 2017 e 2018, teve início em 6 de abril.

Além das telenovelas, a Globo também suspendeu em 16 de março a gravação de quase todos os seus programas de entretenimento. Reprises foram a solução para algumas faixas horárias, como para as atrações dos finais de semana. Na programação exibida de segunda a sexta, o canal tirou do ar os programas Mais Você, Encontro com Fátima Bernardes, Globo Esporte e Se Joga. Com isso, ampliou a programação jornalística, que passou a ter 11 horas diárias consecutivas, entre 4h e 15h (O Globo, 2020). Passado um mês da mudança, a emissora retomou a exibição do programa de Fátima Bernardes e do semanal É de Casa, exibido aos sábados pela manhã. 
Decisão semelhante à da Globo foi tomada pela TV Record em 17 de março, quando também suspendeu a gravação de telenovelas e programas de auditório. Com muitos capítulos já gravados, a emissora conseguiu manter no ar a sua trama do horário nobre até 20 de abril. Para o lugar de Amor sem Igual, interrompida por tempo indeterminado, embora a retomada das gravações tenha sido em 10 de agosto, o canal optou pela reexibição de Apocalipse, trama inspirada na Bíblia e exibida originalmente entre 2017 e 2018. Antes da pandemia, a emissora contava com quatro telenovelas em sua programação diária, sendo três delas reprises. Estas obras seguiram no ar sem nenhuma alteração, duas delas A Escrava Isaura ${ }^{13}$ e Os Mutantes - eram exibidas na faixa vespertina. No horário das 21h30, ia ao ar Jesus.

Os dados de audiência do Sistema Brasileiro de Televisão (SBT) levantados pelo IBOPE $^{14}$ no período entre $20 / 07 / 2020$ a 26/07/2020 revelam que quatro telenovelas ocupam o TOP 10 dos programas mais exibidos pelo canal. São elas: Quando me apaixono, Cúmplices de um resgate e Betty a feia em NY e Chiquititas $^{15}$. Esta última entrou no lugar de As aventuras de Poliana, que teve sua gravação suspensa por conta da pandemia. Todos os demais programas de entretenimento ${ }^{16}$ também foram suspensos, sendo substituídos por edições mais antigas dos mesmos. Entretanto, a audiência ${ }^{17}$ se mobilizou no Twitter para que,

Inspirada no romance de Bernardo Guimarães, publicado em 1875, a telenovela A Escrava Isaura teve sua primeira versão produzida pela Globo em 1976. Escrita por Gilberto Braga e estrelada por Lucélia Santos, a obra original foi exportada para 109 países pela emissora carioca. Em 2004, ganhou uma nova versão na Record, desta vez com a atriz Bianca Rinaldi no papel título. ranking-consolidado-20-07-a-26-07-2020/. Acesso em: 31 jul. 2020. o SBT não conseguiu converter esse fenômeno em ganho de audiência. Por ter poucos programas jornalísticos nos horários nobres e muitas reprises de programas de auditório, o que não agradou ao público, a emissora teve o pior primeiro semestre desde 2014. 
no lugar desses programas, fossem exibidas as telenovelas mexicanas Maria do bairro e $A$ usurpadora.

A Rede Bandeirantes (Band) apresenta apenas uma telenovela em sua grade de programação, pois investe mais na exibição de reality shows. O canal, assim como as outras emissoras, precisou recorrer à reprises por conta da pandemia, e começou a anunciar em abril o retorno de Floribella. Entretanto a substituição, que estava programada para a segunda quinzena de julho, precisou ser adiada duas vezes devido aos atrasos no processo de dublagem da telenovela portuguesa Ouro Verde, do canal TVI, que sairá do ar em setembro. No Twitter oficial da emissora o público reclamou das mudanças nas datas de estreia da reprise, que não foram comunicadas pela Band, e se mostrou bastante ansioso pela volta de Floribella.

No período de pandemia, quando as pessoas passaram a ficar mais tempo em casa, os índices de audiência de televisão aumentaram. A Globo, os canais pagos de notícias, o Canal Viva ${ }^{18}$ e os serviços de streaming foram os mais beneficiados. Dados do Kantar Ibope Media mostram que no primeiro mês de quarentena, a busca maior foi por notícias ${ }^{19}$, mas depois o público passou a preferir programas de entretenimento - com destaque para as reprises de telenovelas na Globo e no Viva. Conforme Stycer (2020), na faixa horária das 7 h às 24h, a Globo registrou aumento médio de um ponto no Painel Nacional de Televisão (PNT) nos primeiros sete meses de 2020 com relação ao mesmo período de 2019.

Em relação ao horário nobre (entre $18 \mathrm{~h}$ e $24 \mathrm{~h}$ ), o crescimento foi de dois pontos, sendo que todas as telenovelas em exibição na faixa horária tiveram aumento de audiência. Segundo dados do IBOPE publicizados por Feltrin (2020a),

18 Criado em 2010, o canal por assinatura do Grupo Globo tem como carro-chefe a exibição de folhetins antigos. Em 10 anos, já foram exibidos 45 títulos, alguns dos quais mais de uma vez, como Vale Tudo (1988). da televisão aberta dos últimos cinco anos ocorreram no referido mês, a maioria registrada pelo Jornal Nacional e pelo reality show Big Brother Brasil, ambos da Globo. No dia 24 daquele mês, à noite, mais precisamente às 20h57min, horário do $J N$, sete em cada 10 TVs das 15 principais regiões metropolitanas do Brasil estavam ligadas - o maior percentual de audiência da pandemia (VOGEL, 2020). 
a Globo mantém média de $32,6 \%$ da audiência ${ }^{20}$, liderando a atração de público no país. Em segundo lugar, com $15 \%$ da audiência, estão os serviços de streaming (aqui incluindo todos os disponíveis no Brasil, como Netflix, Globoplay, Amazon Prime Video, YouTube etc.). Em terceiro está a TV paga (soma de todos os canais), com 13,7\%. A Record aparece com 12\%, seguida do SBT com $10 \%$ e da Band com 3,2\%. Dentre os canais pagos, nos primeiros meses de pandemia, a liderança ficou com o canal de notícias GloboNews. Em junho, o Viva passou a ser o mais visto entre os assinantes da TV fechada (FELTRIN, 2020b).

Nesse cenário, o objetivo desse texto é, na perspectiva do papel da ficção televisiva para a construção da memória social e individual, explorar o consumo de telenovela no contexto da pandemia, destacar o papel das reprises tanto como estratégias das emissoras quanto do ponto de vista de sua audiência e identificar a ocorrência de produção de novos sentidos para as narrativas revisitadas. Um questionário online foi disponibilizado para coletar dados sobre o consumo de telenovelas e reprises antes e durante as circunstâncias da pandemia. No contexto que aborda o período anterior à pandemia nosso objetivo era descobrir se reprises faziam parte do consumo televisivo dos participantes, ou se ocorreu apenas por consequência das estratégias adotadas pelas emissoras frente às paralisações das gravações. Já no cenário de consumo durante a pandemia buscamos conhecer as preferências dos participantes por telenovelas recentes ou clássicas, motivações e percepções acerca das reprises, assim como suas opiniões sobre as estratégias de divulgação dos canais televisivos. O questionário foi divulgado por e-mail e redes sociais (Twitter, Facebook e Instagram), tendo como retorno 265 respostas no período de 20 de Julho a 6 de Agosto.

\section{Telenovela e memória: alguns aspectos}

Em Sujetos telespectadores y memoria social, Mario Carlón (2004) diz que Peter Burke "ao assinalar que os indivíduos tornam seus os acontecimentos 
públicos importantes para seu grupo, que recordam muitas coisas que não experimentaram diretamente, e que uma notícia pode converter-se em parte da vida de alguém, se abre de algum modo a discussão sobre o lugar dos discursos midiáticos na vida social (2004, p. 174) ${ }^{21}$

Carlón trata a televisão de maneira geral, categorizando a programação em transmissão direta/ ao vivo e gravada, onde se estabelece a programação ficcional como a telenovela, as séries e os filmes. Essa categoria corresponde à ficção e a primeira o não ficcional. Na combinatória entre os registros representacionais ficção/ não ficção - e os dispositivos - direto/ gravado, surgem quatro regimes espectatoriais que constituem quatro tipos de telespectadores. São posições extremas e prototípicas nas quais surgem múltiplas situações em que o telespectador se posiciona. Segundo ele, "aconteceu uma multiplicação de campos e de sujeitos telespectadores, e com eles, uma ampliação do campo de possibilidades da memoria compartilhada"22 (CÁRLON, 2004, p. 189).

Mesmo a programação ao vivo, que em princípio não está configurada pelo passado, é puro presente, tem potencial para tornar-se parte da memória coletiva e social. Carlón chama de "extraordinária máquina da memória do acontecer social"23 (CÁRLON, 2004, p. 193), mas alerta que não há consenso. Ele afirma que Paul Virilio considera que as imagens televisivas se relacionam mais com o esquecimento do que com a memória, o que é nomeado por Dubois como "imagem amnésica" e que estaria mais relacionado com a transmissão ao vivo (CARLÓN, 2004).

Opondo-se a essa ideia, Carlón defende que a memória televisiva é muito melhor que a humana "porque cada vez que é consultada volta a dizer/ mostrar exatamente o mesmo"24 (2004, p. 194), citando exemplos de fatos e eventos que

21 "Los individuos hacen suyos acontecimientos públicos importantes para su grupo, que recuerdan muchas cosas que no han experimentado directamente, y que una noticia puede convertirse en parte de la vida de alguién se abre de algún modo la discusión sobre el lugar de los discursos mediáticos en la vida social" (2004, p. 174). 
podem ser recordados por segmentos da audiência como rever jogos de futebol, corridas de fórmula 1, reprises de ficção, como telenovela, filmes e séries. Ou até mesmo rever qualquer programação com objetivo de análise, de pesquisa, pontuando a dimensão da tarefa: "com a quantidade de canais, que emitem 24 horas, os documentos que registram o que acontece produziram uma expansão da memória que a tornaram inabarcável"25 (idem), além disso, a seleção do material é problemática, "porque o registro da memória, ao menos potencialmente, se tornou infinito"26 (CARLÓN, 2004, p. 195). Enfatiza o papel dos meios como elemento na construção da memória social uma vez que recordamos certos acontecimentos a partir da imagem e discurso televisivo: "a memória do visto por imagens televisivas transmitidas diretamente não é individual - ou só individual - mas coletiva, porque junto com o discurso compartilhado, foi construída uma instância supraindividual, o sujeito telespectador"27 (CARLÓN, 2004, p. 197). Graças às coberturas amplas de certas transmissões podemos recordar os mesmos discursos de forma conectada, o que não permite dizer que tenham o mesmo significado para todos os grupos.

No caso do discurso ficcional, a telenovela - enquanto gênero - ocupa um lugar privilegiado na articulação entre uma memória popular e uma memória midiática. Martín-Barbero, ao se referir à linguagem folhetinesca, considera que "os dispositivos que permitem ao folhetim incorporar elementos da memória narrativa popular ao imaginário urbano-massivo não podem ser compreendidos nem como meros mecanismos literários nem como desprezíveis artimanhas comerciais" (MARTÍN-BARBERO, 2001, p. 195). Por ser gênero, a telenovela se constitui a partir de uma lógica narrativa a priori, possui um funcionamento social "[...] que atravessa tanto as condições de produção quanto as de consumo" (p. 195). Esse lugar anterior à obra remete roteiristas, diretores e produtores

"Con la cantidad de canales que emiten veintecuatro horas, los documentos que registran lo que acontece han producido una expansión de la memoria que la han tornado inabarcable" (2004, p. 194). 
às diferentes práticas, símbolos e representações da nossa cultura nacional. Dessas fontes, atuam paralelamente como importantes agentes na construção da memória sobre o nosso país.

Por isso, Lopes $(2003 ; 2014)$ compreende a narrativa melodramática como algo que vai além de mero entretenimento. Esse gênero midiático consagra-se, há pelo menos cinco décadas, como um espaço de problematização do Brasil. Pautas sociais e políticas são projetadas na tela da TV de milhões de brasileiros e brasileiras diariamente, invadindo seus lares, podendo adquirir forte caráter propositivo. Aludindo à Benedict Anderson, Lopes (2003, p. 30) afirma: "A novela tornou-se uma forma de narrativa sobre a nação e um modo de participar dessa nação imaginada". Dessa articulação entre o seu caráter narrativo e participativo, a telenovela contribui para que lugares, identidades e costumes de diferentes partes da nação ganhem visibilidade, passando a "existir" para milhões de brasileiros. Desse modo, através da sua interpelação, a narrativa ficcional forja um sentimento de pertencimento através da elaboração de uma memória coletiva sobre a nação. Para Lopes (2014), ganha estatuto de documento de época, uma vez que serve como fonte de dados sobre diferentes temporalidades e territorialidades do país, um legítimo repositório de nossa herança cultural. Retomando Martín-Barbero, também podemos considerar que "[...] no folhetim, aparece uma relação outra para com a linguagem: aquela que, quebrando as leis da textualidade, faz da própria escritura o espaço de decolagem de uma narração popular, de um contar a" (2001, p. 194).

Lopes (2003) ainda alerta para o papel das reprises que, em sua perspectiva, funcionam como um dispositivo de memória. "Quando assistimos a reprises ou a programas especiais que relembram trechos de telenovelas, reavivamos as lembranças que são associadas aos elementos emocionais que fazem parte da história do próprio telespectador e, por isso, revivemos um determinado sentimento" (LOPES, 2014, p. 10). A autora cita como exemplos as reprises do Vale a pena ver de novo, as que são veiculadas no Canal Viva e, também, os remakes. Em diálogo com Martín-Barbero (2001), podemos localizar as reprises 
no âmbito dos formatos industriais que, ancoradas na memória, conectam-se às práticas de recepção, constituindo gramáticas da ação, que diz respeito a como o sujeito se relaciona com o gênero ou texto midiático em questão. Isso será contemplado quando apresentarmos os dados levantados em questionário. Na seção seguinte, veremos como a Globo vem definindo estratégias no que diz respeito às suas reprises.

\section{Globo e as estratégias de reprise}

Em março de 2020, Amor de Mãe, telenovela do horário nobre, havia conquistado audiência após um começo com altos e baixos nos índices do IBOPE $^{28}$. Elogiada pela crítica por promover inovações estéticas e na linguagem, a obra adentrou seu quarto mês em exibição alcançando suas melhores marcas. O $100^{\circ}$ capítulo, que foi ao ar em 19 de março e marcou uma virada importante na história, chegou a registrar 37 pontos no Painel Nacional de Televisão (PNT). Dois dias depois, o trabalho de estreia de Manuela Dias despedia-se do público sem data prevista para retornar à grade de programação, saída motivada pela decisão da emissora de suspender a gravação de todas as telenovelas e programas de entretenimento como medida de prevenção à propagação do novo coronavírus. Pela primeira vez em seus 55 anos, a Globo interrompeu a produção de seu principal produto.

Mesmo sem capítulos inéditos para exibir, foi nas telenovelas que a emissora encontrou a estratégia para manter a fidelidade do público, com a decisão de reprisar títulos antigos. Pesquisas internas e o êxito obtido pelo canal pago Viva, um dos líderes de audiência da TV por assinatura, embasaram os critérios de seleção das reprises. Além do canal aberto e do Viva, a Globo usou a mesma estratégia para ampliar a base de assinantes do Globoplay. Em maio, começou a disponibilizar uma telenovela antiga no catálogo do seu

A telenovela estreou em 25 de novembro de 2019 com índices de audiência considerados baixos para o horário em seu primeiro mês no ar, com média de 29 pontos no Painel Nacional de Televisão (PNT) - a pior registrada pela Globo em três anos para a faixa horária (Na Telinha, 2020). Após alterações de rumo no roteiro, em janeiro começou a recuperação e em março a média semanal ficou acima dos 31 pontos no PNT (ANDRADE, 2020). 
serviço de streaming a cada 15 dias - no total, serão 50 títulos. A primeira foi A Favorita, exibida originalmente em 2008 e sem nenhuma reprise anterior. Depois, entraram Tieta29 (1989), Explode Coração (1995), Estrela-Guia (2001), Vale Tudo (1988) e Laços de Família (2000). Ainda estão previstas Vamp (1991), Quatro por Quatro (1994), Pai Herói (1979), entre outras (G1, 2020). Diretora de conteúdo do Globoplay, Ana Carolina Lima afirmou que a ação explora "[...] a memória afetiva do brasileiro. Quem nunca se lembrou de uma passagem da infância ou da juventude ao ouvir a trilha sonora ou ao rever uma cena de uma novela clássica" (G1, 2020).

Explorando essa memória, a Globo tenta fazer com que o público permaneça mais tempo em sua plataforma. Segundo Erick Brêtas (2020), diretor de serviços e produtos digitais da empresa, ao disponibilizar as telenovelas, que têm cerca de 180 capítulos, a ideia é "fazer com que o público do Globoplay não fique tanto tempo sem entrar no sistema". Com base em dados do setor de inteligência, que analisa o comportamento do consumidor na plataforma, a empresa verificou a perda de usuários quando terminam de assistir a um conteúdo mais curto, como uma série ou um documentário (BRÊTAS, 2020). Aliado a isso, conforme Brêtas, a Globo também tem como meta a recirculação ou "o jogo entre janelas", que consiste em fazer o sujeito circular entre TV aberta, streaming e TV fechada. Aqui, pode-se citar o exemplo de Malhação, que conta com uma base de fãs muito grande e ativa nas redes sociais. Para efetivar essa estratégia de jogo de telas, a Globo optou pela reprise da temporada Viva a Diferença (2017-2018), que vai ganhar um spin-off30 no Globoplay em novembro de 2020.

Atrair o público mais jovem é um dos focos da Globo. Para divulgar as obras que entraram no Globoplay - muitas delas exibidas quando jovens adultos, adolescentes e crianças nem eram nascidos - foram criadas campanhas

29 Para ver as tele novelas reprisadas pela TV Globo entre as décadas de 1970 até agosto de 2020, ver notas 2 a 6.

30 Spin off é o produto derivado de outro. No caso de Malhação, a temporada Viva a Diferença da telenovela terá uma série derivada que dará continuidade à história escrita por Cao Hamburguer, exibida entre 2017 e 2018 . A nova versão, chamada As Five, mostrará como estão as cinco protagonistas seis anos após o término da trama. 
publicitárias com linguagem atual (para Tieta, o vídeo produzido teve como trilha sonora o ritmo funk).

A Globo retomou as gravações de Amor de Mãe e Salve-se Quem Puder em 10 de agosto de 2020 - as outras duas telenovelas (Malhação e Nos Tempos do Imperador) seguem suspensas. Sob um rígido esquema de segurança sanitária, o trabalho precisou se adaptar e servirá de protocolo para os demais ${ }^{31}$.

\section{Pistas sobre a recepção das reprises: resultados de uma enquete}

A partir dos dados fornecidos por 265 pessoas que responderam ao questionário disponibilizado online, das quais $62,6 \%$ são mulheres, $37 \%$ são homens e 0,4\% (uma pessoa) declarada não-binária, apresentaremos alguns resultados a respeito de suas práticas antes e durante a pandemia. Essas pessoas são provenientes de diversas regiões ${ }^{32}$ do Brasil e com diferentes profissões $^{33}$. Antes da pandemia, 40\% delas disseram assistir a telenovelas apenas eventualmente e $27 \%$ diariamente. reduzir o número de pessoas nos sets de gravação. Assim, cada grupo de atores grava em horários e dias alternados reduzindo a produção diária de 25 para 10 cenas por dia (BITTENCOURT, 2020). Para cenas de beijos, diretriz ainda mais severa: os atores são confinados em um hotel e fazem novo exame antes de gravar as cenas com contato físico. E o hábito de usar máscaras deverá ser incluído no roteiro e nas imagens (PADIGLIONE, 2020). Com o ritmo de trabalho mais lento, o plano é só levar ao ar os novos capítulos em 2021, quando as duas telenovelas estiverem com as gravações encerradas - algo previsto inicialmente para novembro (PADIGLIONE, 2020). Grande do Sul foi o mais expressivo com 129 respostas, sendo as cidades de Porto Alegre (62) e Ijuí (18) as mais mencionadas. Na região Sudeste foram 59 respostas dos estados de São Paulo (25), Rio de Janeiro (20), Belo Horizonte (13) e Espírito Santos (1). Na região Nordeste 35 respondentes de todos os estados: Bahia (8), Rio Grande do Norte (5), Sergipe (5), Maranhão (5), Pernambuco (3), Paraíba (3), Ceará (2), Piauí (2) e Alagoas (2). Na região Norte foram 35 respostas: Tocantins (33), Rondônia (1) e Pará (1). Na região Centro-Oeste seis respondentes: Mato Grosso (2), Mato Grosso do Sul (1), Brasília (2), e no Distrito Federal (1). dois relações públicas, sociólogos, produtores, historiadores, profissionais liberais. Também um artesão, enfermeiro, cientista, segurança, do lar, secretário, bancário, roteirista, psicólogo, crediarista, pedagogo, assistente social, operador de dados, arquivista, estatístico, telemarketing, empresário. 


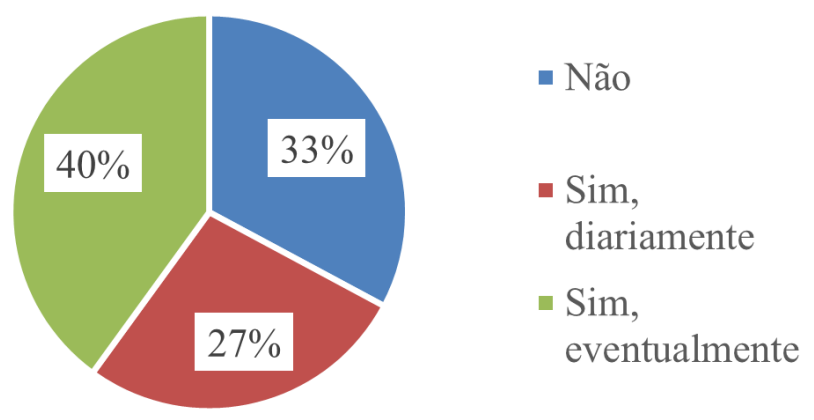

Gráfico 1: consumo de telenovelas antes da pandemia Fonte: os autores

Assim, em termos gerais, por volta de 2/3 dos respondentes são assistentes do gênero, assiduamente ou de vez em quando, e apenas 1/3 (33\%), não assistem telenovelas. Quanto às reprises, os dados revelam maiores diferenças entre as respostas:

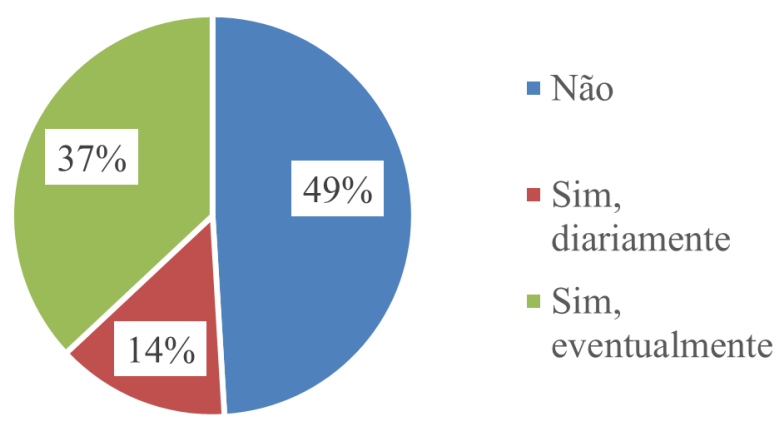

Gráfico 2: consumo de reprises antes da pandemia

Fonte: os autores

Quase a metade dos respondentes (49\%) afirmou não assistir a telenovelas reprisadas; $37 \%$ assistem eventualmente e $14 \%$ assistem sempre. Considerando os que assistem eventualmente e os que assistem sempre, mais da metade dos respondentes ( $51 \%$ ) tem as reprises como parte de seu cardápio de programação televisiva. 
Dentre os $51 \%$ que assistem reprises ${ }^{34}$ (135 pessoas), temos o seguinte cenário:

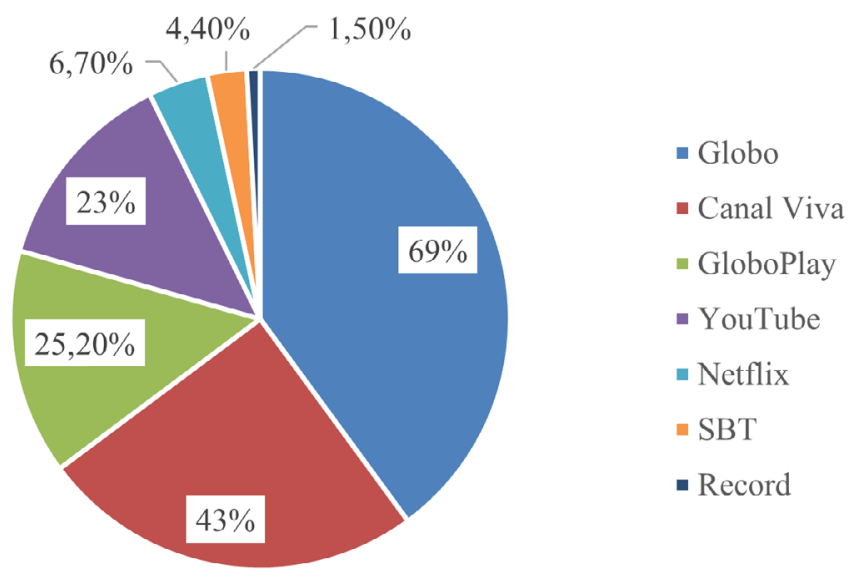

Gráfico 3: canais e serviços utilizados para ver reprises antes da pandemia Fonte: os autores

A maioria (69\%) o faz pelo programa Vale a pena ver de novo (Globo). O Canal Viva, emissora paga, é o segundo mais acessado para tal (43\%). E em terceiro lugar é usada a plataforma de streaming Globoplay $(25,2 \%)$. É notório, portanto, que todas as formas mais acessadas para o consumo de reprise concentram-se em canais filiados à Rede Globo. Na sequência, aparecem YouTube (23\%); Netflix (6,7\%); SBT (4,4\%); Record (1,5\%). Nas demais possibilidades de acesso como DVD, Amazon Prime Video, e sites piratas, que não constam no gráfico 3, foi destacada apenas uma resposta para cada plataforma citada.

Por outo lado, durante a pandemia, 171 pessoas (65\%) estavam acompanhando ou já tinham visto alguma reprise, o que corresponde a bem mais da metade dos respondentes, conforme ilustrado abaixo no gráfico 4: 


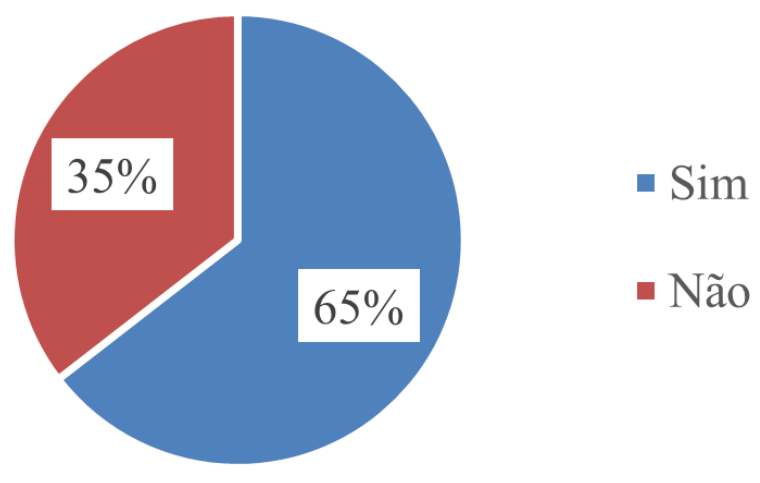

Gráfico 4: reprises de telenovelas durante a pandemia

Fonte: os autores

Desta maioria, 52\% delas estava vendo a reprise pela primeira vez; $29 \%$ não havia visto a telenovela quando foi veiculada originalmente e $19 \%$ já haviam visto a primeira reprise exibida pelo canal.

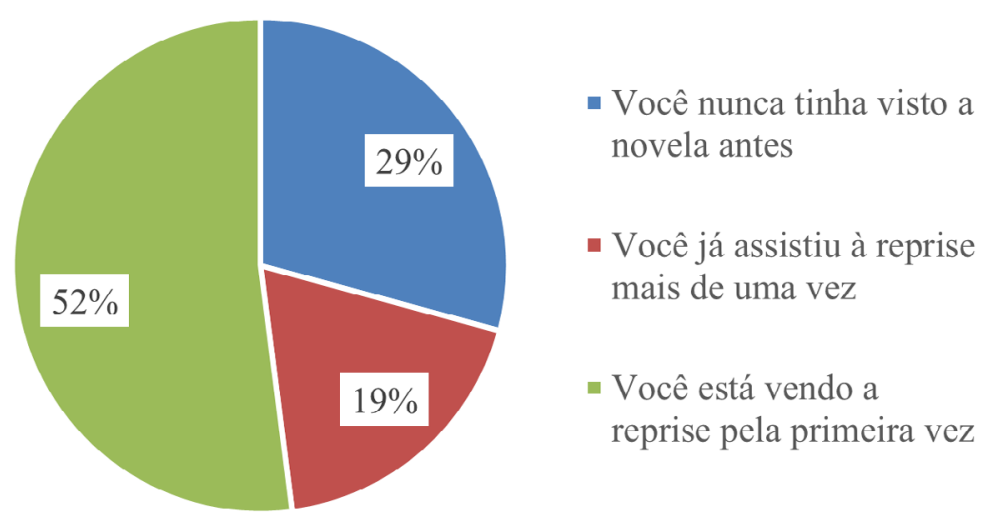

Gráfico 5: conhecimento sobre as reprises assistidas durante a pandemia Fonte: os autores

Ou seja, 29\% dos respondentes, por volta de 1/3, estão aproveitando a oportunidade para conhecer a obra em exibição, possivelmente possibilitado pelas reprises em horários normais. O restante, ou seja, 32,5\% não assistiu e nem estava assistindo reprises. 
Dentre as 121 pessoas que estavam assistindo à telenovela reprisada pela primeira vez ou viram mais de uma vez, a maioria, ou seja, 55\%, tem preferência por um recorte temporal na escolha da reprise:

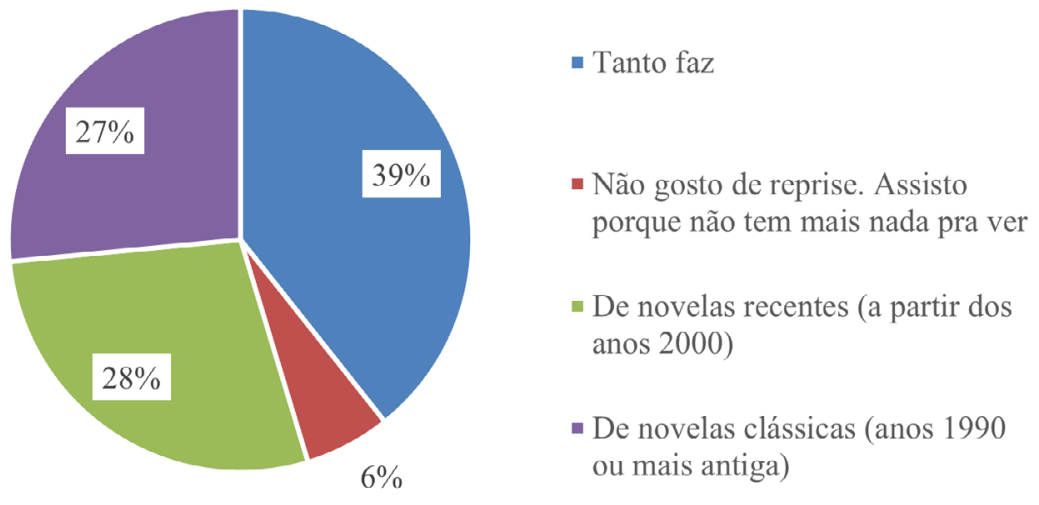

Gráfico 6: preferências para assistir à novela reprisada pela primeira vez Fonte: os autores

No gráfico 6 observamos que 28\% prefere telenovelas recentes (a partir dos anos 2000), enquanto $27 \%$ prefere as veiculadas nos anos 1990 ou anteriormente. A época de veiculação original como critério preponderante na eleição das reprises favoritas marca o duplo papel das narrativas ficcionais reprisadas: tanto como dispositivo de entretenimento, quanto de memória. Essa articulação também se faz presente nas motivações para assisti-las como poderá ser visto mais adiante. Uma fatia considerável, de 39\% de pessoas, entretanto, afirma não ter critérios na escolha da reprise e 6\% assiste porque não tem nada para fazer. Quatro pessoas deram respostas abertas: duas delas comentando que o critério é "a telenovela ser boa", outra afirmando que tem preferência por telenovelas de cinco ou seis anos atrás, ou que tenha marcado uma década; e outra que "qualquer telenovela que desperte o interesse".

No que se refere às motivações para assistir às reprises ${ }^{35}$, a maioria expressa uma relação de afeto com a narrativa, indo ao encontro da afirmação 
da diretora de conteúdo da Globoplay, apresentada mais acima, e das reflexões teóricas sobre a vinculação das audiências com conteúdos ficcionais armazenados na memória (MARTÍN-BARBERO, 2001; LOPES, 2014).

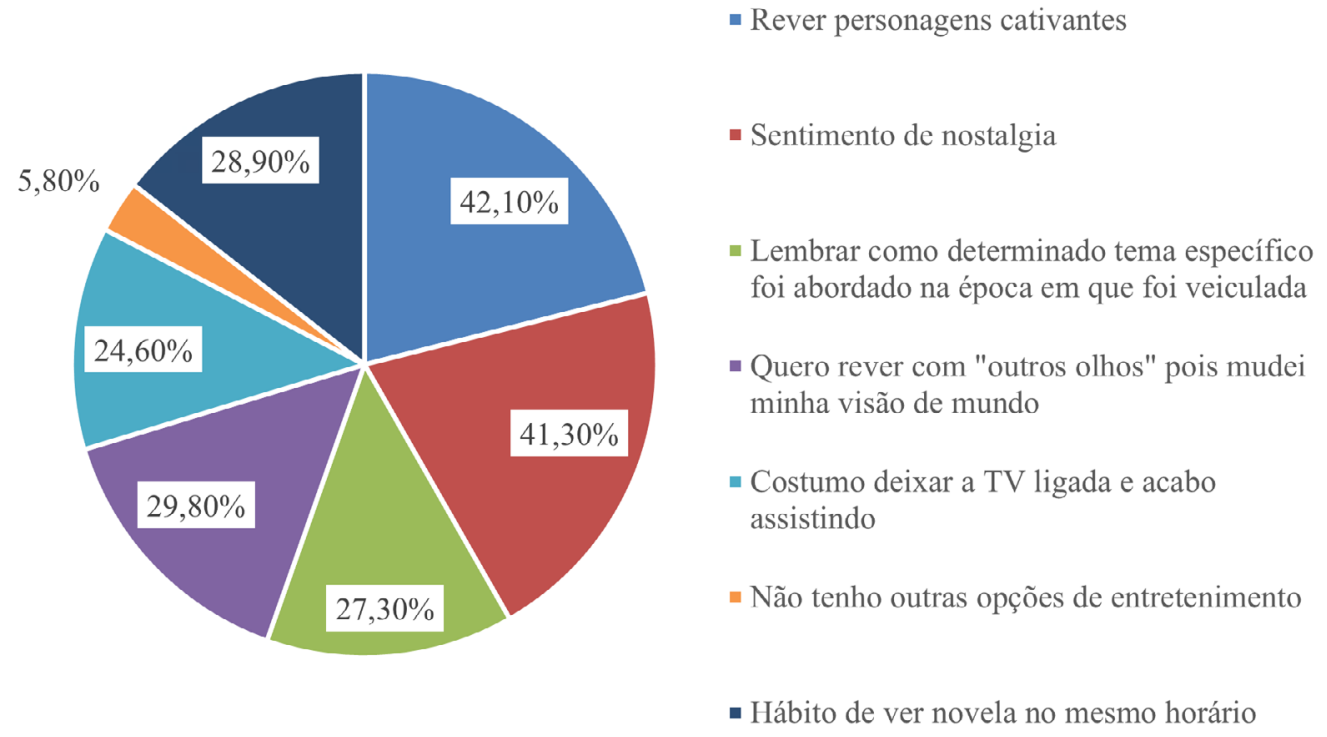

Gráfico 7: motivações para assistir às novelas reprisadas novamente Fonte: os autores

No gráfico 7 podemos visualizar que $42,1 \%$ assiste para rever personagens cativantes e $41,3 \%$ por sentimento de nostalgia. Em seguida, aludem às tematizações da narrativa: 29,8\% pelo interesse de rever uma trama "com outros olhos", 28,9\% assiste pelo hábito de ver telenovela no mesmo horário e $27,3 \%$ para lembrar como determinado tema foi tratado à época de sua exibição. Depois, $24,6 \%$ porque deixam a TV ligada e acabam assistindo; e 5,8\% assiste pela falta de outra forma de entretenimento. Ou seja, há uma parcela de 32,4\% de pessoas que assistem à reprise porque a prática faz parte de sua rotina organizada pelo fluxo televisivo. Como respostas, também temos o caso de duas pessoas que têm curiosidade sobre aspectos tecnológicos, de linguagem e atuações. Essa motivação levanta a hipótese de que podem ser fãs, pois é uma das práticas favoritas desse segmento de receptores (JENKINS, 2009). Por fim, sete têm outros motivos: apreciação 
técnica, estética e da narrativa, sendo que a maior parte assiste em rituais de socialização familiar, situação em que a TV fica ligada com a telenovela no ar.

Sobre a percepção da reprise que estava no ar, $43 \%$ considera que houve mudança parcial no modo de vê-la; 35\% mudou totalmente a percepção, e $22 \%$ não modificou sua percepção sobre a trama, conforme resumido no gráfico 8 abaixo:

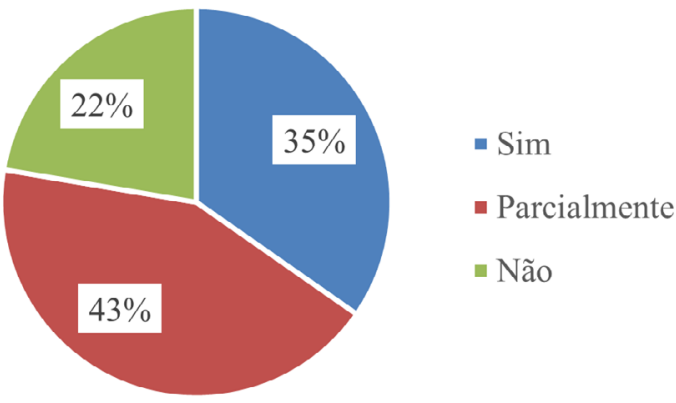

Gráfico 8: mudanças de percepção sobre a trama da novela reprisada Fonte: os autores

É possível inferir que $77 \%$ teve alguma mudança de percepção sobre tema e/ou personagens com o passar do tempo. Desse total, temos o seguinte cenário sobre o que ocorreu no processo de recepção da reprise:

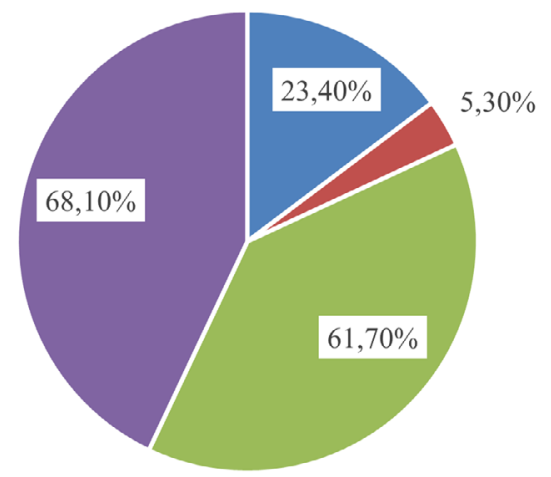

- Gostei mais da história

- Gostei menos da história

- O meu julgamento de valor sobre determinadas personagens foi outro

- A minha impressão sobre a abordagem de determinado tema social foi outra

Gráfico 9: novas avaliações sobre a trama da novela reprisada Fonte: os autores 
Como vemos, 68,1\% reconhece que a impressão sobre a abordagem de determinado tema social foi outra; $61,7 \%$ que mudou o julgamento de valor sobre determinadas personagens; $23,4 \%$ que gostou mais da trama ao assistir à reprise, e, ao contrário, 5,3\% gostou menos. Conforme atestado por Lopes (2003), a telenovela representa um espaço de problematização do Brasil. Portanto, ver uma telenovela reprisada é revisitar uma realidade em que outros padrões de comportamento e regimes de representação davam os contornos dos debates, anseios e moralidades de um tempo passado. Os demais aspectos apontados foram que a qualidade dos diálogos e o humor da trama foram percebidos de maneira mais positiva. Outra mudança de percepção foi considerar que se trata de uma boa distração. As diferenças perceptivas podem indicar a diversidade de motivos e aspectos que envolvem a relação dos receptores com as telenovelas, indo da recepção por puro lazer e descontração ao fã que se compromete com aspectos mais técnicos e estéticos da narrativa.

Para a maioria, rever a telenovela fora do seu contexto histórico alterou a percepção sobre temas sociais ou julgamentos de valores. Um dos exemplos nesse caso, é do personagem Crô (Marcelo Serrado) em Fina Estampa, exibida entre março e setembro. Considerado icônico em 2011, quando foi exibida originalmente, o personagem passou a ser rejeitado por parte do público em 2020: "o jeito cômico, caricato e submisso à patroa Tereza Cristina (Christiane Torloni)", que fez sucesso no começo da década de 2010 e levou o personagem a ganhar dois filmes posteriores ao folhetim, recebeu críticas nas redes sociais, e "entre elas, estavam a de que Crô mostra um estereótipo do 'homossexual divertido', já ultrapassado para os dias de hoje" (PAGNO, 2020). Essa mudança de percepção relaciona-se com o argumento de Chauí (1994) de que, ao relembrar, os sujeitos não apenas revivem ou repetem algo do passado, mas refazem e refletem sobre o já vivido com a compreensão de vida que têm no presente.

Dos 50 respondentes que nunca haviam assistido às telenovelas reprisadas e que estavam assistindo no momento, as motivações são as seguintes: 54\% 
credita às personagens; $48 \%$ aponta os temas abordados; $34 \%$ remete-se aos atores; $28 \%$ à sinopse; $24 \%$ à moda, tecnologia e ambientação. As demais motivações com percentuais mais baixos foram: localização em que se passa a história (16\%), o diretor $(14 \%)$ e trilha sonora $(12 \%)$. Os percentuais menos expressivos e que não constam no gráfico foram o isolamento social $(4 \%)$, por ser uma telenovela clássica $(4 \%)$, por ter mais tempo livre $(4 \%)$, passa no horário disponível (4\%), para fazer companhia a familiares (4\%). Com apenas uma resposta: enquadramento e movimentos de câmera, não havia visto ainda, lembrança de infância. Um resumo desse panorama pode ser visualizado abaixo:

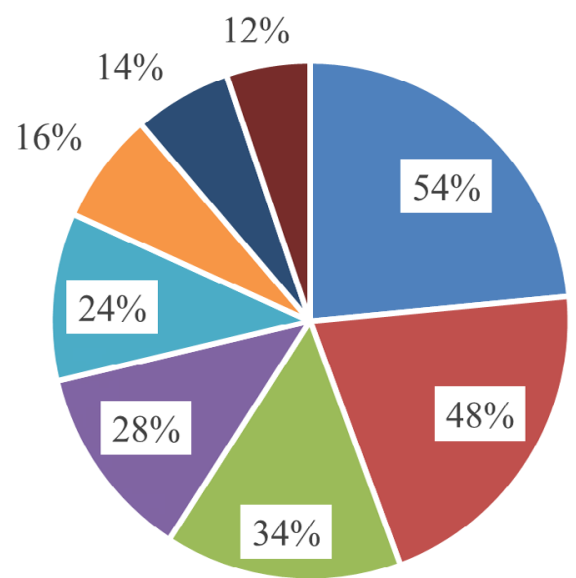

- As personagens

- Os temas abordados (questões sociais, políticas, culturais...)

- Os atores/atrizes que interpretam as personagens

- A sinopse

- A moda, as tecnologias e ambientação dos espaços domésticos da época

- O local geográfico em que se passa a história

- O diretor/roteirista

- A trilha sonora

Gráfico 10: motivações para assistir à novela reprisada pela primeira vez Fonte: os autores

Dos que estão acompanhando reprises, 81,9\% assiste pela Globo; 30,4\% pelo Globoplay; 25,7\% pelo Canal Viva; 9,9\% pelo YouTube; 2,9\% pelo SBT; 2,3\% pela Netflix; $1,8 \%$ pela Record; $1,2 \%$ por DVDs, conforme figura 11 abaixo. Pela inexpressividade, ficou de fora do gráfico a Guigo TV e sites piratas, cada opção com uma resposta apenas. 


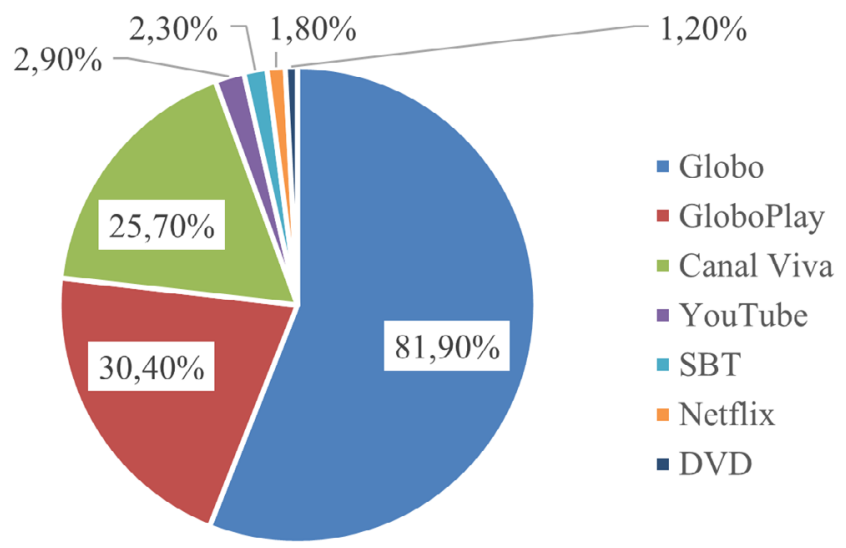

Gráfico 11: canais e serviços preferidos para assistir às reprises

Fonte: os autores

De todas as telenovelas mencionadas pelos que estão assistindo reprises, as mais citadas foram ${ }^{36}$ (em ordem decrescente): Fina Estampa e Totalmente Demais (ambas com 58 menções), Êta Mundo Bom (47), Malhação: Viva a diferença (28), Chocolate com Pimenta (25), O Clone (25), Novo Mundo (22), Tieta e A Favorita (ambas com 16 menções), Vale Tudo e Brega \& Chique (14), Avenida Brasil (8), Verdades Secretas (6) e Cheias de Charme (5).

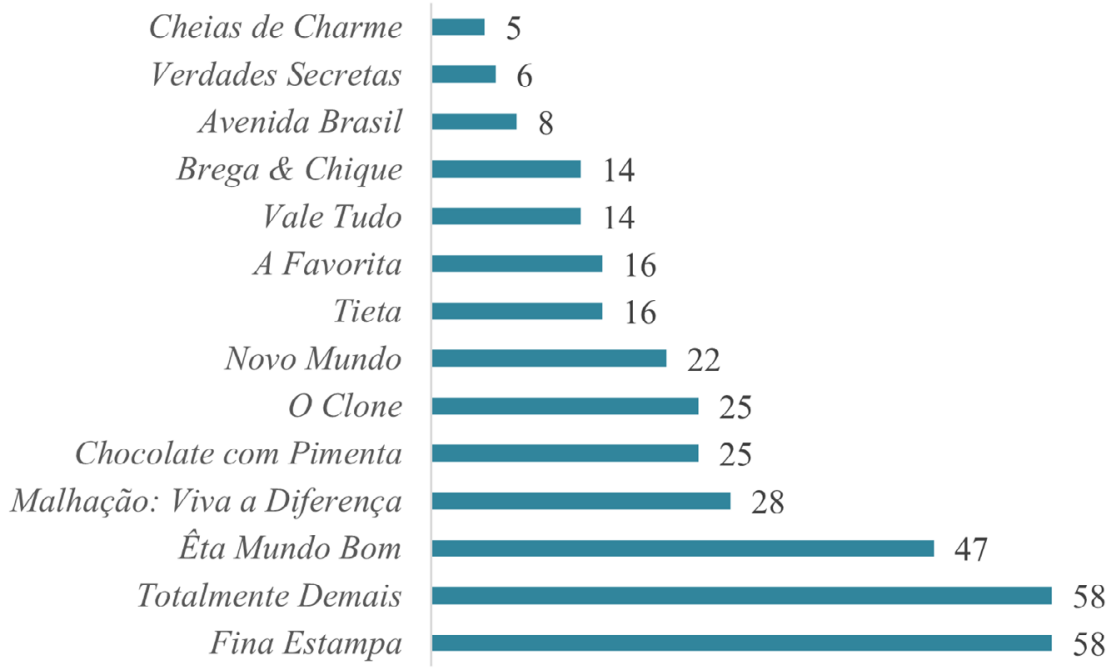

Gráfico 12: novelas reprisadas assistidas durante a pandemia Fonte: os autores 
As reprises de Belíssima, Mulheres apaixonadas, A Força do Querer, Rock Story, Explode Coração, Sangue Bom, Apocalipse (Record) e Betty em Nova York (SBT) foram mencionadas duas vezes cada. As reprises da Globo citadas apenas uma vez foram: Além do tempo, Caminho da Índias, Quatro por Quatro, Rei do Gado, Sete Vidas, Por Amor, Meu Pedacinho de Chão, Deus Salve o Rei, Geração Brasil, Estrela Guia, Senhora do Destino, Cobras e Lagartos e Morde e Assopra.

Apenas uma vez também foram indicadas as reprises das outras emissoras: Usurpadora, Cuna de Lobos (veiculada com o título Ambição), Cúmplices de um Resgate, As aventuras de Poliana, Quando Me Apaixono e Sortilégio, Chiquititas e As histórias de Ana Raio e Zé Trovão ${ }^{37}$ do SBT; e Escrava Mãe, da Record. Estas telenovelas citadas menos de cinco vezes não foram contempladas no gráfico acima.

Dentre as dez telenovelas mais citadas, observa-se a hegemonia da Globo. Metade das narrativas preferidas está sendo veiculada pela emissora em sua programação televisiva tradicional; e a outra metade apenas no Globoplay. Vale ressaltar o desempenho do Globoplay nas respostas, que neste caso aparece à frente do Canal Viva como uma alternativa para quem consome telenovela. Além de confirmar dados do IBOPE vistos anteriormente, que mostram o streaming em expansão no Brasil, esse resultado dá pistas de que a estratégia da Globo em fazer um forte investimento em sua plataforma - tanto em novos conteúdos disponibilizados quanto em publicidade - pode estar dando resultados. E ainda sinaliza que as telenovelas podem ter apelo para o consumo imersivo tanto quanto as séries. Como diferencial, aquelas detêm a competência de trazer à tona recordações e reavivar a memória coletiva.

Para finalizar, a maioria dos respondentes gostou da estratégia dos canais de exibir reprises durante a pandemia. Os motivos da aprovação e reprovação são apresentados no gráfico 13, abaixo: 


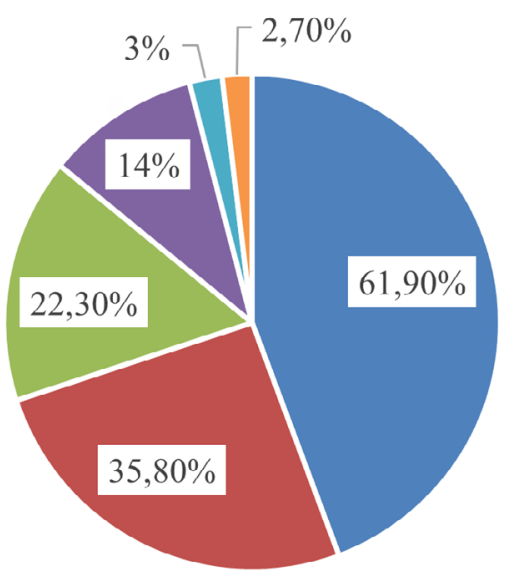

- Gostei, pois achei uma atitude responsável

manter os atores e equipe em isolamento

- Gostei, pois tem muita novela boa para rever

- Gostei, mas não concordei com os títulos

escolhidos

- Para mim é indiferente ser reprise ou inédita

- Não gostei, preferia que tivessem optado por outro tipo de programa

- Não acompanhei as decisões dos canais

Gráfico 13: percepções sobre a estratégia dos canais em reprisar novelas na pandemia Fonte: os autores

Para $61,9 \%$ das pessoas foi uma atitude responsável manter os atores e equipe em isolamento, $35,8 \%$ apontaram o fato de haver muitas telenovelas boas para serem exibidas. Porém, embora $22,3 \%$ tenha aprovado a estratégia, não gostou dos títulos escolhidos para as reprises, ao passo que para $14 \%$ é indiferente ver uma telenovela inédita ou reprise. Apenas $3 \%$ não aprovou a estratégia e preferiu outro tipo de programa. E outras $2,7 \%$ disseram não ter acompanhado as decisões dos canais.

\section{Vale a pena ver de novo?: considerações finais}

O texto deu contornos ao cenário pandêmico mobilizador de mudanças estruturais nos veículos de comunicação televisiva, forçando adaptações bruscas da grade de programação em meio às incertezas provocadas pelo novo coronavírus. A veiculação de reprises foi uma dessas estratégias das emissoras, poupando equipes de produção e atores de se exporem, criando, assim, condições para o isolamento dos colaboradores ligados ao entretenimento.

No caso específico da Rede Globo, a presença das telenovelas na TV aberta, no Canal Viva, e no Globoplay, assim como os investimentos em marketing (BRÊTAS, 2020) nesta plataforma, indicam que a emissora se manteve atenta às 
práticas de convergência como estratégia de sobrevivência em meio à pandemia. Sobre as estratégias publicitárias, Brêtas comenta que os recursos persuasivos adotados foram em direção a uma "linguagem mais abusada", se aproximando do público jovem que não tem a nostalgia enquanto motivação para assistir às telenovelas clássicas. Uma hipótese possível para a preferência por telenovelas da emissora, por parte dos receptores investigados, pode ser reflexo de sua política publicitária, uma vez que o carro chefe da emissora continua sendo o seu próprio produto.

O contexto da pandemia evidenciou que as telenovelas também são relevantes como estratégia para serviços de streaming, especialmente o da Globo. Tanto que uma expressiva parte dos entrevistados revelou estar acompanhando algum título pelo Globoplay. É necessário, porém, ponderar que parte desse movimento pode ter relação com os títulos escolhidos pela empresa para o catálogo da plataforma. Com telenovelas mais antigas, o Globoplay atendeu a uma antiga reivindicação dos seus usuários (VAQUER, 2019), que até então só as encontravam no Canal Viva, dependendo assim da grade de programação da emissora para poder assistir. Além disso, as obras que entraram em exibição no canal aberto, como Fina Estampa, despertaram certa rejeição por parte do público. Dessa forma, como o hábito de assistir à TV já está incorporado no cotidiano, algumas pessoas podem ter optado por seguir as suas telenovelas preferidas via Globoplay.

Em outro âmbito, tomando em consideração os dados referentes aos receptores, podemos observar que, enquanto quase metade dos respondentes não assistiam à reprises antes da pandemia, com o contexto de isolamento social somado à leva de telenovelas reprisadas em horários além do já conhecido Vale a Pena Ver de Novo, esse índice diminui. Nesse cenário excepcional, a maioria está acompanhando as reprises, cujas motivações variam desde uma reapreciação estética, a rememoração de uma vinculação afetiva com personagens, até simplesmente pela convivência com pessoas que acompanham reprises, nesse caso sendo uma minoria. A motivação dos demais evoca uma relação muito próxima 
com a valorização da memória, mas apesar disso, a assistência da reprise não se resume a um simples "relembrar" a trama. No movimento de retornar à narrativa assistida outrora, novos sentidos são inaugurados pela maioria dos informantes.

Se a percepção mudou, é porque a mudança do contexto provavelmente atuou nesse sentido. Não podemos deixar de mencionar os debates emergentes dos últimos anos sobre gênero, raça, sexualidade, bem como as polarizações políticas e ideológicas que invadiram a mídia, as redes sociais e os lares brasileiros. Um sintoma dessa observação é que um índice significativo de receptores afirmou não ter aprovado os títulos escolhidos para reprise. A exemplo de um deles, que deixou escrito: "Infelizmente escolheram Fina estampa para reprisar". Esta trama, como já mencionamos, fez emergir uma série de discussões sobre o machismo praticado pelo personagem Quinzé, bem como sobre discursos homofóbico dirigidos a Crô, personagem homossexual, afeminado e caricato, e vítima constante de humilhações que foram usados como alívio cômico da narrativa. Tais oposições de sentido, à época de sua veiculação, não haviam emergido com a ênfase de hoje.

A exibição de reprises possibilitou o surgimento de novas problematizações sobre representação de mulheres, LGBTs e pessoas negras que alçaram visibilidade no debate midiático. Isso nos remete à capacidade da telenovela de pautar a agenda pública, além de servir como um repositório da nossa memória, registrando as transformações da sociedade (LOPES, 2014). Os títulos mais antigos reprisados na pandemia como Tieta e Vale Tudo, no Globoplay, ambos da década de 1980, revelam vários aspectos da cultura brasileira - da moda à música - mas também sobre questões políticas, que voltaram a ser discutidos e analisados em 2020, sendo objetos de comparações com o contexto atual em redes sociais e até mesmo nas propagandas veiculadas pela Globo para o lançamento de Vale Tudo no Globoplay.

Ao mesmo tempo, nesse momento em que nos privamos dos nossos afetos em carne e osso, poder rever uma narrativa também serve como um alento, dado que muitas pessoas valorizaram o sentimento de nostalgia e carinho em relação às ambientações mais antigas e personagens que marcaram época. 
Por fim, nesse contexto de pandemia, consideramos que a telenovela serviu como um arquivo de nossa memória moral e afetiva. Sendo assim, podemos afirmar que sim: vale a pena ver de novo.

\section{Referências}

CARLÓN, M. Sobre lo televisivo. Dispositivos, discursos y sujetos. Buenos Aires. La Crujía, 2004.

CHAUÍ, M. Os trabalhos da memória. In: BOSI, E. Memória e sociedade: lembranças dos velhos. 3a. ed. São Paulo: Companhia das Letras, 1994.

FERNANDES, I. Memória da telenovela brasileira. São Paulo: Brasiliense, 1987.

Guia Ilustrado TV Globo: novelas e minisséries/Projeto Memória Globo. Rio de Janeiro. Jorge Zahar Ed., 2010.

JENKINS, H. Cultura da convergência. São Paulo: Aleph, 2009.

LOPES, M. I. V. de. Memória e identidade na telenovela brasileira. In: Anais da Compós XXIII. Belém: UFPA, 2014. Disponível em: http://compos.org.br/encontro2014/ anais/Docs/GT12_ESTUDOS_DE_TELEVISAO/templatexxiiicompos_2278-1_2246. pdf. Acesso em: 11 jun. 2020.

Telenovela brasileira: uma narrativa sobre a nação. In: Comunicação \& Educação, v. 26, jan.-abr. 2003.

MARTÍN-BARBERO, J. Dos meios às mediações: Comunicação, cultura e hegemonia. Rio de Janeiro: Editora da UFRJ, 2001. 


\section{Fontes sobre audiência e estratégias das emissoras}

ANDRADE, V. Vai deixar saudade? Amor de Mãe sai do ar no melhor momento da novela no Ibope. Notícias da TV. 18 mar. 2020. Disponível em: https://noticiasdatv. uol.com.br/noticia/audiencias/vai-deixar-saudade-amor-de-mae-sai-do-ar-nomelhor-momento-da-novela-no-ibope-34632. Acesso em: 18 ago. 2020.

BITTENCOURT, C. Primeira semana de gravação de 'Salve-se quem puder' e 'Amor de mãe' é positiva. Extra. 15 ago. 2020. Disponível em: https://extra.globo.com/ tv-e-lazer/telinha/primeira-semana-de-gravacao-de-salve-se-quem-puder-amorde-mae-positiva-24586417.html. Acesso em: 16 ago. 2020.

BRÊTAS, E. O futuro das plataformas de streaming e a experiência do Globoplay. In: Conecta+ Unisinos. 15 jul. 2020. Disponível em: https://www.youtube.com/ watch?v=fhz09mZTVk4\&list=PL4P9VVumOg5HgY_1KNMEYQNyWOixPHG64\&ind ex $=2 \& \mathrm{t}=0$ s. Acesso em: 15 jul. 2020.

FELTRIN, R. Streaming já é o $2^{\circ}$ maior ibope do país e só perde para Globo. Uol. 8 jul. 2020a. Disponível em: https://tvefamosos.uol.com.br/noticias/ ooops/2020/07/08/streaming-ja-e-o-2-maior-ibope-do-pais-e-so-perde-paraglobo.htm. Acesso em: 11 ago. 2020.

- Viva é o canal pago mais visto do país e deixa GloboNews em 20. Uol. 5 ago. 2020b. Disponível em: https://tvefamosos.uol.com.br/noticias/ ooops/2020/08/05/viva-e-o-canal-pago-mais-visto-do-pais-e-deixa-globonewsem-2.htm. Acesso em: 11 ago. 2020.

G1. Globoplay vai incluir uma novela clássica a cada duas semanas na plataforma. 21 maio 2020. Disponível em: https://g1.globo.com/pop-arte/noticia/2020/05/21/ 
Globoplay-vai-incluir-uma-novela-classica-a-cada-duas-semanas-na-plataforma. ghtml. Acesso em: 15 ago. 2020.

MEMÓRIA GLOBO. Vale a pena ver de novo. Disponível em: https://memoriaglobo. globo.com/exclusivo-memoria-globo/projetos-especiais/vale-a-pena-ver-de-novo/. Acesso em: 4 ago. 2020.

NA TELINHA. Amor de Mãe chega a 30 capítulos com o pior Ibope em três anos. 2 jan. 2020. Disponível em: https://natelinha.uol.com.br/novelas/2020/01/02/ amor-de-mae-chega-a-30-capitulos-com-o-pior-ibope-em-tres-anos-138955.php. Acesso em: 18 ago. 2020.

O GLOBO. TV Globo muda programação por causa do coronavírus. 16 mar. 2020. Disponível em: https://oglobo.globo.com/cultura/revista-da-tv/tv-globo-mudaprogramacao-por-causa-do-coronavirus-24309209. Acesso em: 5 jun. 2020.

PADIGLIONE, C. Atores serão confinados para fazer cenas de beijo, conta diretor de Amor de Mãe. TelePadi. 15 ago. 2020. Disponível em: https://www1.folha.uol. com.br/ilustrada/2020/08/atores-serao-confinados-para-fazer-cenas-de-beijoconta-diretor-de-amor-de-mae.shtml. Acesso em: 16 ago. 2020.

PAGNO, M. Marcelo Serrado diz que Crô "não é um palhaço sem alma", mas entende críticas: "Hoje, o autor escreveria de outra forma". GaúchaZH. 22 jun. 2020. Disponível em: https://gauchazh.clicrbs.com.br/cultura-e-lazer/tv/noticia/2020/06/ marcelo-serrado-diz-que-cro-nao-e-um-palhaco-sem-alma-mas-entende-criticashoje-o-autor-escreveria-de-outra-forma-ckbqis6t8004w0162kvik40b5.html. Acesso em: 24 ago. 2020.

STYCER, M. Globo cresce no Ibope em 2020 e ganha público entre crianças e adolescentes. Uol. 11 ago. 2020. Disponível em: https://tvefamosos.uol.com.br/ 
colunas/mauricio-stycer/2020/08/11/com-reprises-globo-cresce-e-ganha-publicoentre-criancas-e-adolescentes.htm. Acesso em: 11 ago. 2020.

TELEDRAMATURGIA. Vale a pena ver de novo. Disponível em: http://teledramaturgia. com.br/reprises-2/vale-a-pena-ver-de-novo/. Acesso em: 7 ago. 2020.

VAQUER, G. Globo começará a disponibilizar novelas antigas no Globoplay até o fim do ano. Observatório da TV. Disponível em: https://observatoriodatv.uol. com.br/noticias/globo-comecara-a-disponibilizar-novelas-antigas-no-globoplayate-o-fim-do-ano. Acesso em: 25 ago. 2020.

VOGEL, M. A TV em tempos de Covid-19: impactos e mudanças no comportamento da sociedade. 3 abr. 2020. Disponível em: https://www.kantaribopemedia.com/ a-tv-em-tempos-de-covid-19-impactos-e-mudancas-no-comportamento-dasociedade/ Acesso em: 16 jun. 2020.

Submetido em: 02 set. 20 | aprovado em: 14 out. 20 